\title{
Biblioteca como lugar de memória e eco de conhecimento: um olhar sobre "O Nome da Rosa"
}

\author{
César Augusto Castro
}

\begin{abstract}
Resumo
Analisa-se a biblioteca como lugar de memória e espaço de produção e circulação de conhecimento, a partir do texto O Nome da Rosa , de Umberto Eco, tomado como referência. Evidenciam-se as diferentes formas de criação e destruição desse espaço de memória em diferentes sociedades, bem como as diferentes estratégias de salvaguarda de seus acervos. Defende-se a biblioteca como espaço de guarda e conservação das materialidades documentais produzidas no passado, como fontes de informação para uma compreensão aprofundada do presente e o bibliotecário, por sua vez, como guardião do conhecimento. Enfocam-se as tecnologias como recursos auxiliares na recuperação de informações produzidas no passado, sem, contudo, fetichizá-las. Conclui-se que, entre as instituições envolvidas com a preservação da memória, a biblioteca tem papel preponderante na preservação e disseminação do passado - e, portanto, da identidade - de um povo.
\end{abstract}

\section{Palavras-chave}

História das bibliotecas; Biblioteca e memória; Preservação documental; Livro e leitura

\section{Library as a memory place and knowledge's echo: a look at "The Name of the Rose"}

\begin{abstract}
This paper analyzes the library as a place of memory and space of knowledge production and circulation, departing from the text $O$ Nome da Rosa written by Umberto Eco as a reference. Different forms of creation and destruction of that memory space in different societies are evidenced, as well as different strategies of safeguard of their collections. Thus, the paper defends libraries as spaces of safekeeping and conservation of the materiality of documents produced in the past as sources of information for a deeper comprehension of the present, and the librarian, in his turn, as a knowledge guardian. It focuses on the technologies as auxiliary resources for retrieval of information produced in the past, without making them a fetish. It concludes that, among the institutions involved in the memory preservation, libraries have a preponderant role in the preservation and dissemination of the past - and thus of the identity - of peoples.
\end{abstract}

\section{Key words}

Libraries history; Library and memory; Documental preservation; Book and reading 


\section{ARTIGO}

\section{INTRODUÇÃO}

O Nome da Rosa ${ }^{1}$ é, sem dúvida, uma das obras clássicas da literatura mundial recente. Seu autor, Umberto Eco, ao mergulhar no universo das bibliotecas medievais, retrata o poder que estas exerceram, bem como as estratégias na concepção das estruturas físicas (grandes labirintos) e organizacionais utilizadas como impeditivos do acesso ao conhecimento.

Uma abordagem emanentista da história exposta possibilita compreender o poder dos bibliotecários como guardiões da memória, ao impedir a aproximação de leitores de textos considerados impuros e impróprios. Mas permite igualmente identificar de que forma a ordem moral e religiosa se reveste de significações intencionais para justificar e naturalizar a censura por parte do regime eclesiástico (LE GOLF, 1993). Refletindo essa dicotomia conflitante em suas ações e reações, Jorge, o bibliotecário, se apresenta, por um lado, como dotado de imensa capacidade organizativa e, por outro, mostra-se ardiloso, ao planejar assassinatos com grande discrição.

Ao se apropriar das reminiscências de Adson de Melk registrada em velhos e "bastante pobres" manuscritos, Eco traz à tona "fios de tantos e tão confusos eventos" ocorridos no interior de um mosteiro beneditino do século XIV. A produção de um texto, sobretudo romanesco e de fundo histórico como é O Nome da Rosa, sempre exige intensa dedicação do autor. Assim, Eco afirma que teve "momentos mágicos de grande cansaço físico e excitação motora”, em seu esforço para retratar um lugar, um tempo e, sobretudo, a história de diferentes homens, que se colocavam a favor ou contra a preservação da memória individual e coletiva.

Com uma estrutura setenária da história expõe claramente o cotidiano de um mosteiro medieval, narrando acontecimentos que têm como pano de fundo a rotina clerical. A história se passa nos anos de 1316 a 1334, durante o papado de João XXII. Sete

${ }^{1}$ Para a elaboração deste texto, utilizamos a edição brasileira da Editora Record de 1986 (Coleção Mestres da Literatura Contemporânea). O excesso de citações em língua latina dificulta, de certo modo, a sua fluência, mas não chega a comprometer a fruição desse texto tão rico em detalhes sobre a realidade medieval, aguçando a curiosidade do leitor no que diz respeito ao suspense presente nas suas 562 páginas.

(C) Revista Digital de Biblioteconomia e Ciência da Informação, Campinas, v. 4, n. esp., p. 01-20, 2006 - ISSN: 1678-765X. 
assassinatos misteriosos ocorrem ao longo de uma semana, todos ligados a uma tentativa de barrar o acesso ao terceiro volume da Poética, de Aristóteles, considerado profano pelo bibliotecário. Os fatos transcorrem nos sete dias da semana, retratando as minúcias do cotidiano eclesiástico, das Matinas, Laudes, Primeira, Terceira, Sexta, Nona, Vésperas e Completas, horas em que os monges tinham determinadas obrigações religiosas.

Ao instaurar a dúvida sobre se Jesus Cristo sorriu alguma vez em sua vida, de alguma situação ou de alguém, o autor critica impiedosamente determinadas questões, no seu entender sibilinas e ridículas, que os teólogos debatiam entre si. Muitos eminentes teólogos de então defendiam que tal demonstração subjetiva de gracejo era incompatível com a missão do filho de Deus, o qual certamente não teria demonstrado indícios de alegria. Os argumentos utilizados para fundamentar essa assertiva eram baseados nos Evangelhos, pois em nenhum deles se descreve alguma manifestação de riso por parte de Cristo.

Frei de Baskerville e Adson Von Melk, os protagonistas da história, começam a investigar aquelas mortes misteriosas, sem saber que todas elas estão ligadas ao livro de Aristóteles, oculto num dos armários da complexa biblioteca, que "nasceu segundo um desenho que permaneceu obscuro a todos durante séculos e que a nenhum dos monges é dado conhecer”. Pretendia-se, desse modo, proteger o livro, que seria uma "criatura frágil, sofre a usura do tempo, teme os roedores, as intempéries, as mãos inábeis”. Ao bibliotecário Jorge, cabia defendê-los, "não só dos homens, mas também da natureza, e dedica sua vida a esta guerra contra as forças do ouvido, inimigo da verdade” .

O livro evidencia também o embate clássico entre a fé e a razão, assim como o esforço da Igreja Católica em manter inabaláveis seus dogmas e critérios de verdade. Dessa forma, a instituição milenar garantia a ordem social e aquinhoava bens materiais. Para tanto, a Igreja vendia indulgências, controlava a produção e a circulação do conhecimento e aterrorizava e penalizava a todos aqueles que cometessem atos considerados profanos ou duvidassem do poder punitivo da "Santa Madre Igreja”. ( MATTOSO, 2001). 
Através da narrativa "ecoista”, o leitor se apropria do cotidiano daqueles homens no interior de uma abadia medieval. Percebe, igualmente, a correlação de forças entre aqueles que organizavam e controlavam a produção e circulação do conhecimento em geral e os que infringiam as regras de acesso a obras proibidas, na procura do conhecimento.

A biblioteca retratada por Eco metaforiza, num sentido mais amplo, o sonho de todos os povos, desde as mais antigas civilizações, de ter sob a sua guarda toda a memória do mundo, como fonte de importância e poder. Por outro lado, evidencia as estratégias de destruição da identidade de uma sociedade através da censura e da queima de livros.

Como labirinto terreno e espiritual, aquela biblioteca tinha mais livros que qualquer outra biblioteca cristã do Oriente ou do Ocidente, o que a tornava objeto de desejo e admiração por parte de outras abadias. O scriptorium, como centro de cópias, de miniaturização e de ilustração, abrigava uma equipe de especialistas no tratamento e confecção de livros. Dirigidos pelo bibliotecário, esses profissionais executavam seu trabalho do nascer ao pôr do sol, seguindo férreas regras. O bibliotecário - e tão somente ele - detinha o conhecimento total das obras guardadas nas salas e armários.

O presente texto, discute a biblioteca como espaço de memória e fonte de inspiração e objeto de destruição dos homens em todas as civilizações e em todos os tempos. Mas são certamente essas instituições, de história tão conturbada, que desempenham o indispensável papel de guarda e preservação da memória individual e coletiva de uma sociedade.

Nesse mister, o bibliotecário é o profissional que constrói arqueologias para tratar, organizar, conservar e divulgar os objetos que armazena. Para isso, monta catálogos, elabora bibliografias, estabelece regras e recorre às atuais tecnologias de informação e comunicação. 


\section{ARTIGO}

\section{BIBLIOTECAS: lugar de continuidade, de rupturas e de tradições}

Historicamente, a Idade Média tem sido percebida como um tempo vazio de sentido e de circulação do conhecimento. Le Golf (1995), ao contrário, defende a idéia de que esse período foi marcado por forte movimento cultural e intelectual. Isto se tornou mais evidente principalmente no século XII, após a criação das universidades, que chegaram a mudar o cotidiano das cidades. Os estudantes que circulavam por ruas, praças e bordéis transformam lugarejos pacatos em templos de algazarras e de debates sobre Filosofia, Direito, Medicina e Artes (MICHELET, 1992).

Para os provincianos radicais, as universidades traziam desonra, discórdia e imoralidade; para os entusiastas da modernidade, no entanto, essas instituições oportunizavam ganhos financeiros (com vendas de livros, aluguéis de albergues) e, principalmente, a democratização do acesso ao conhecimento (ALEXANDRE-BIDON; LORCIN,1998). A descrição dos estudantes medievais feita por Moulin (1994) na obra $A$ vida cotidiana dos estudantes na Idade Média evidencia as mudanças propiciadas pelo surgimento das universidades, as quais mantêm seu status e sua importância até os dias atuais, embora seu significado e seu perfil tenham, evidentemente, mudado ao longo dos séculos.

Nesse contexto de efervescência intelectual, as bibliotecas desempenhavam um papel privilegiado na formação das mentalidades, rivalizando com as salas de aula, quer as instaladas no interior das instituições, quer as públicas e as privadas. Assim, elas se constituíam em "centros de estudos, locais de sociabilidade culta e de troca de informações e idéias, além de serem lugares de leitura” (BURKE, 2003, p. 56), para uma pequena elite que gozava do privilégio de saber ler.

Como suporte do texto, o livro, manuscrito ou impresso, escrito em tabletes de argila, papiros ou pergaminhos, ou no formato eletrônico, constitui sempre um instrumento para a compreensão parcial da realidade. Essa compreensão é propiciada pela relação que se estabelece entre atores sociais - autor e leitor - mediatizados pela linguagem, como 
afirma Deleuze (1992). Trata-se de uma relação de modo algum linear, na medida em que vários fatores a permeiam e nela interferem, como a cosmovisão do autor e do leitor e suas experiências individuais e coletivas:

Longe de serem escritores, fundadores de um lugar próprio, herdeiros dos servos de antigamente mas agora trabalhando no solo da linguagem, cavadores de poços e construtores de casas, os leitores são viajantes; circulam nas terras alheias, nômades caçando por conta própria através dos campos que não escreveram. (CERTEAU, 1994, p. 269-270).

Na Idade Média, como em qualquer época, o processo de destruição de livros é perpetrado por várias motivações. No caso em tela, ocorre como conseqüência do antagonismo entre fé e razão. Esse embate, cuja supremacia é da primeira, foi a forma encontrada pela Igreja Católica para se contrapor ao crescente avanço de idéias heréticas Grant (2001). E foi essa a motivação para a catalogação e censura de obras permitidas a circular entre as restritas comunidades de leitores. Trata-se daquilo que Certeau (1992) denomina de "leitura mística” e que Chartier (1982) entende como o conjunto de procedimentos de leitura recomendada (nihil obstat) ou não recomendada (obstat) a um grupo minoritário de "iluminados" que regulam costumes e estabelecem normas de conduta para os cristãos. Esse foi um papel desempenhado pela Igreja ${ }^{2}$, consubstanciado pelo controle exercido pelos bibliotecários, como descreve o texto de Eco.

Mas o controle, ao mesmo tempo em que busca afastar o leitor de determinados textos, cria o desejo pelo proibido, ensejando “caças não autorizadas” (CERTEAU, 1994, p. 56). É o que fazem os monges d'O Nome da Rosa, ou seja, criam estratégias e táticas para romperem com as tecnologias disciplinares e com a "microfísica do poder" (FOUCAULT, 2004).

\begin{abstract}
Se é verdade que toda a parte se estende e se precisa a rede da 'vigilância', mais urgente ainda é descobrir como é que a sociedade inteira não se reduz a ela: que procedimentos populares (também 'minúsculos'e cotidianos) jogam com os mecanismos da disciplina e não se conformam com ela a não ser para alterá-los; enfim, que 'maneiras de fazer' formam a contrapartida, do lado dos consumidores (ou 'dominados'?), dos processos mudos que organizam a ordenação sociopolítica? (CERTEAU, 1994, p. 41).
\end{abstract}

\footnotetext{
2 A exemplo do Index, lista de livros autorizados e não autorizados pela igreja e que até hoje é feito nas editoras católicas, cujos livros sempre trazem a indicação "nihil obstat”, que quer dizer "nada obsta”, ou seja, indicação de que o livro pode ser publicado e lido
}

(C) Revista Digital de Biblioteconomia e Ciência da Informação, Campinas, v. 4, n. esp., p. 01-20, 2006 - ISSN: 1678-765X. 
Um exemplo elucidativo dessa “caça não autorizada” é apresentado por Ginzburg, em O queijo e os vermes (GINZBURG, 1987). Nessa obra, a partir de pesquisa sobre processos inquisitoriais, o autor conta a história de Domenico Scandella, mais conhecido como Minocchio, moleiro do nordeste da Itália no final do século XVI. O relato descreve as estratégias do personagem para obter as materialidades de leitura e a origem das suas idéias heréticas à luz da ortodoxia católica, que o levaram à morte na fogueira em praça pública.

Outro exemplo é dado por Ítalo Calvino, em Um general na biblioteca (2001). Nesse romance, o general Fedina, em vez de cumprir o seu papel de censor, descobre, com a ajuda de um velho bibliotecário, curiosidades e o universo de conhecimentos guardados na biblioteca da cidade imaginária de Panduria.

Em Fahrenheit 451, obra de autoria de Ray Bradbury (1953) quando uma jovem prefere ser queimada ao lado da sua vasta biblioteca em vez de permanecer viva. Assim, as formas exercidas pelas instâncias de poder que regulam e ordenam as práticas leitoras encontram sempre seus contraventores, como Minocchio e Fedina.

\begin{abstract}
Parece-me importante situar, nesse debate, o poder exercido pelos bibliotecários na definição do que é e do que não é permitido ler. Imbuídos das chaves de acesso através das técnicas classificatórias, catalográficas e de suas concepções políticas e ideológicas, esses profissionais podem contribuir para o controle, a destruição de textos e lugares de memória ou para a contravenção da ordem. (BELO, 2002).
\end{abstract}

Como exemplo de controle ou censura perpetrada por bibliotecários, tem-se a participação das bibliotecas e dos bibliotecários na formação e expansão do pensamento e das práticas nazistas na Alemanha ${ }^{3}$. Esse período foi, aliás, considerado por Battles (2003) como o período áureo da profissão, na medida em que eram os bibliotecários que determinavam o que povo deveria e, acima de tudo, o que não deveria ler. Isso conferia status aos profissionais da biblioteconomia, que passavam a uma posição de destaque na sociedade, contando com o apoio governamental. Assim, os bibliotecários ajudaram a

${ }^{3}$ Coube ao bibliotecário e simpatizante do nazismo Wolfgang Hermann, o controle e devastação dos livros e bibliotecas judaicas. Foram igualmente destruídas as obras vendidas em tabacarias, cafés, bancas de jornal, especialmente as histórias de amor, de detetive e de outros gêneros, denominadas por esse nazista de "bordéis literários”. 


\section{ARTIGO}

compilar listas de autores que deveriam ser censurados, eliminaram rivais das pequenas bibliotecas comerciais de empréstimo e purgaram preventivamente suas coleções de tudo aquilo que [...] denominavam literatura de asfalto (BATTLES, 2003, p. 77).

Exemplos de contravenção são as estratégias utilizadas pelos estudantes judeus e por alguns bibliotecários não simpatizantes do Reich, para preservar a memória do povo alemão. Isso nos lembra novamente Fahrenheit 451, no qual há relatos de pessoas que escondiam livros em paredes ou tetos, como forma de livrá-los das chamas dos bombeiros. À noite, na cidade fictícia criada pelo seu autor, incendiavam-se os debates sobre escritores e suas obras, como forma de mantê-los vivos na memória de cada homem ou mulher. Um paralelo desse fato narrado por Bradbury pode ser encontrado no último capitulo d'O Nome da Rosa , quando Guilherme e Adso tentam salvar da biblioteca em chamas alguns pergaminhos: "enchi com eles dois sacos de viagem, abandonando coisas que me eram úteis para salvar aquele mísero tesouro” (ECO, 1986, p. 561).

O fogo, como elemento mítico, tem sido a forma usual de destruição de livros e bibliotecas. Em todas as sociedades, do passado ao presente, as chamas têm feito arder o pensamento de toda uma coletividade: “Ao destruir com fogo, o homem brinca de Deus, dono do fogo da vida e da morte” (BÁEZ, 2006, p. 26).

A primeira grande biblioteca incendiada de que se tem relato foi a Biblioteca de Alexandria, como retrata Luciano Cânfora em A biblioteca desaparecida (1989). Ao presenciar a destruição da mais importante biblioteca da antiguidade, Teódato diz a César “O que está queimando aqui é a memória da humanidade”(SILVA 2006, p. 85). Do mesmo modo, Báez (2006) ao perguntar a um velho professor de história medieval em Bagdá sobre saques e incêndios nas bibliotecas, arquivos e museus, obteve a seguinte resposta: "Nossa memória já não existe. O berço da civilização, da escrita e das leis foi queimado. Só restam cinzas” (BÁEZ, 2006, p. 12).

Mas outras formas de destruição também têm sido utilizadas, a depender do poder criativo do exterminador. A destruição de acervos e de instituições de memória também 


\section{ARTIGO}

resulta, muitas vezes, da ausência e/ou descontinuidade de políticas públicas de preservação de acervos de arquivos e bibliotecas, da falta de apoio governamental para a aquisição de materiais bibliográficos e eletrônicos, da inexistência de bibliotecas escolares em muitas instituições de ensino. Enfim, há uma infinidade de atitudes que, por não usarem elementos naturais, restringem o acesso das camadas populares ao livro, à leitura, enfim: à informação.

Na Idade Média, portanto, o livro, como elemento sagrado, devia ser mantido sob a guarda de bibliotecários, pela fragilidade do suporte ou do conteúdo da obra ou pela existência de uma cópia única, o original, que Berlioz (1996, p.65) denomina de "controle de penas e tintas”. Atualmente, mesmo diante de todo o avanço na produção e reprodução da informação e da diversidade de formatos, muitos textos (sobretudo os manuscritos oriundos de séculos passados) não podem ser consultados por pesquisadores, para que não venham a ser destruídos. Isto é tão mais verdadeiro quando se consideram aqueles que o tempo e o descaso dos governos brasileiros, em todas as suas esferas, têm historicamente relegado ao abandono. Esse veneno intencional dos governos, escondido em cada folha ou página que manuseamos, não causa a morte do pesquisador, mas sem dúvida contribui para aniquilar a memória nacional.

Pesquisa que realizamos sobre instituições asilares no Brasil do século XIX nos forneceu a dimensão do poder destrutivo intencional de bibliotecas e arquivos por parte de governos. Em dez bibliotecas e arquivos públicos visitados em diferentes unidades da Federação, constatamos a precariedade do estado de conservação de livros, jornais e principalmente de manuscritos. Para desvendarmos essa realidade, recorremos às estratégias medievais utilizadas nos scriptorium: “réguas, trinchas e luvas” (MCMURTRIE, 1997, p. 99) e, sobretudo, a um grande poder de concentração, durante horas de trabalho de transcrição.

Nessa verdadeira arqueologia do saber, percebemos que, mesmo na sociedade atual, denominada da informação, o bibliotecário, o historiador e o pesquisador precisam transitar nas fronteiras entre a tradição e as novas tecnologias da informação, entre a

(C) Revista Digital de Biblioteconomia e Ciência da Informação, Campinas, v. 4, n. esp., p. 01-20, 2006 - ISSN: 1678-765X. 
biblioteca de papel e a biblioteca virtual, entre a tradição e a pós-modernidade. E certamente esse é o grande desafio imposto às bibliotecas e aos bibliotecários desde Alexandria: navegar pelo novo sem renegar ou relegar ao esquecimento as marcas do passado.

\section{Biblioteca: texto, história e memória}

Os documentos manuscritos e impressos armazenados em bibliotecas, arquivos e museus contribuem para o resgate e a produção de memórias perdidas em papéis nem sempre conservados, trazendo ao conhecimento público fragmentos de informações corroídas pelo tempo. Assim, dificulta-se a montagem de um corpus textual sobre o conjunto de práticas e saberes construídos por homens e mulheres do passado. Nesse sentido, diz Nora (1993) que é necessário criar e conservar arquivos, assim como comemorar aniversários, preservar monumentos, santuários e demais lugares onde se ancora e se exprime a memória coletiva. Com isso, possibilita-se o rompimento com as determinações do tempo e do espaço, como afirma Halbwachs (1990).

A construção, preservação e valorização dos lugares de memória contribuem para que, no futuro, não se estabeleça, como contraponto à sociedade do conhecimento, a sociedade do esquecimento, cujo presente será descontínuo e ausente de sentido. Mas são palavras, expressões, riscos e rabiscos das materialidades textuais do passado que corporificam e dão sentido ao presente, a partir dos enunciados, das práticas discursivas que emanam das séries documentais depositadas em caixas, armários e estantes de arquivos e bibliotecas.

Entretanto, os lugares de memória não são espaços de recolhimento da poeira dos enunciados, mas constituem o espaço em que ocorre a ressurreição de uma multiplicidade de enunciados oferecidos ao tratamento e à manipulação (FOUCAULT, 2004, p. 147). Esses enunciados - manuscritos, iconográficos, sonoros, digitais - trazem a marca de um tempo, de um lugar, das estratégias de agregação e de apropriação de determinados valores, conceitos e normas de ajustamento, de tramas e jogos de poder, de rituais e rupturas de grupos sociais organizados. 


\section{ARTIGO}

Recorrer a esses enunciados requer a superação de duas dificuldades. A primeira, mais geral, consiste na "sistemática destruição das fontes históricas e dos suportes da memória coletiva” (NUNES; CARVALHO, 1993, p. 28-29). A segunda, mais específica, requer do pesquisador o enfretamento da documentação das diferenças entre os sistemas de classificação dessas fontes documentais, "o que representa os múltiplos poderes que os arquivos encarnam” (NUNES; CARVALHO, 1993, p. 28-29). Esse enfrentamento exige do pesquisador uma “operação técnica” de separar, agrupar e transformar documentos, dandolhes um novo aspecto pela transcrição, pela recópia ou pela fotografia, mudando sua feição, seu lugar, seu tempo e, por conseguinte, seu estatuto (CERTEAU, 1982).

Ao tomarmos as fontes históricas, porém, devemos compreender que elas trazem as marcas, as intenções e as visões de mundo e de sociedade de quem as escreveu, uma vez que "todas as práticas, sejam econômicas ou culturais, dependem das representações utilizadas pelos indivíduos para dar sentido ao mundo”, como afirma Hunt (1992, p. 25).

Para nós, isso implica um olhar angustiado de pesquisadores e bibliotecários em torno de massas documentais disformes, que "exalam no silêncio o perfume de vidas há muito extintas” (DUBY, 1993, p. 56). Isto porque, de cada maço de documentos, emergem fatos, estatísticas, formas de expressão que, "no início, não passam de um andaime leve, mas que já encerram no todo as formas do futuro edifício” (DUBY, 1993, p. 56). E é só lentamente que as mãos e a criatividade dão vida às personagens, às tramas, às formas, manchando de tinta, por fim, folhas de papel em branco.

A preservação e a conservação de papéis como repositórios de memória têm sido objeto da ação de homens e mulheres desde a sua mais remota existência. Todavia, na mesma proporção - como anteriormente tratado - o poder de destruição dos lugares de memória (arquivos, bibliotecas e museus) tem ocupado espaço em todas as sociedades por motivos políticos, ideológicos ou religiosos (CASTRO, 2005). Esse fato não é produto da ignorância ou da falta de consciência, mas sim de homens que, "sob pressão de mitos apocalípticos” (BÁEZ, 2006, p. 27), destroem documentos, que não são apenas objetos físicos, mas veículos de memória: “Esse vínculo poderoso entre livro e memória faz com 
que um texto deva ser visto como peça-chave do patrimônio cultural de uma sociedade, de toda a humanidade” (BÁEZ, 2006, p. 24).

Nesse sentido, esses lugares de memória são instâncias de poder e centro das teatralidades cotidianas (CERTEAU, 1994) que, envoltas em névoas de técnicas de organização numa ordem labiríntica, distribuem o conhecimento em armários e estantes, como fazia Jorge, em $O$ Nome da Rosa , ou através dos utensílios informáticos, como atualmente se faz.

A biblioteca, portanto, é mais que um espaço arquitetônico: "É um lugar de diálogo com o passado, de criação e inovação, e a conservação só tem sentido como fermento dos saberes e motor dos conhecimentos, a serviço da coletividade inteira” (BARATIN; JACOB, 1995, p. 9). Como instituição, a biblioteca é o cruzamento utópico entre o sonho extravagante de deter todo o saber produzido pela humanidade e as restrições técnicas e espaciais para a concretização desse idílio. É também o resultado claro e preciso das políticas de seleção, conservação e divulgação de textos, imagens e sons. Por fim, é um “desígnio intelectual, um projeto, um conceito imaterial que dá sentido e profundidade às práticas de leitura, de escrita e de interpretação” (BARATIN; JACOB, 1995, p. 10).

Sendo assim, os lugares de memória, pelo poder de representação que encerram, contribuem para a compreensão do presente a partir do passado, trazendo, assim, perspectivas de delineamentos do futuro (BURKE, 2003). Por outra via, esses lugares somente se tornam plenamente significativos quando seus leitores / usuários passam a se apropriar das informações ali guardadas. E é nisso que reside a possibilidade de sua permanência ou de sua destruição, por trazerem em seus muros e estantes o registro de memórias, tempos, lugares e concepções.

A destruição de bibliotecas é uma tentativa de eliminar qualquer evidência material - livros, documentos e obras de arte - que possam atestar às gerações futuras "que pessoas de diferentes tradições étnicas e religiosas haviam compartilhado uma herança comum” (BATTLES, 2003, p. 187), a exemplo do que aconteceu em Saravejo e do que ocorre no Iraque. 


\title{
ARTIGO
}

Neste trabalho, defendo a idéia de que biblioteca é um lugar de memória e espaço de armazenamento das materialidades textuais produzidas em tempos e localidades diversos e que desempenha, mesmo com todo o avanço tecnológico, o papel de guardiã do conhecimento. Não no sentido de guardar para si o patrimônio material e imaterial produzido por homens e mulheres do passado, mas de, através dele, possibilitar o acesso a um passado disforme que pode ganhar sentido nas mãos de pesquisadores, bibliotecários e leitores.

\begin{abstract}
Museus e bibliotecas se tornaram heterotopias onde o tempo não cessa de acumular e que não alcança o seu auge. No século XVII, mesmo no final do século, museus e bibliotecas eram a expressão de escolhas individuais. Mas a idéia de acumular tudo, de estabelecer um tipo de 'arquivo geral', o desejo de ter, num único lugar, todos os tempos, todas as épocas, todas as formas, todos os gostos, a idéia de construir um lugar que congregue todos os tempos que são, por si só, fora do tempo e inacessíveis à destruição do tempo, o projeto de organizar, deste modo, um tipo de acumulação perpétua e indefinida do tempo em um lugar imóvel, esta idéia de todo pertence à nossa modernidade. O museu e a biblioteca são heterotopias próprias da cultura ocidental do século XIX. (FOUCAULT, 1984).
\end{abstract}

Advogo a idéia de que o bibliotecário é um guardião desse patrimônio e que, de posse de instrumentais teóricos, técnicos e tecnológicos, pode contribuir para desterritorializações do acervo sob sua custódia, através do uso da informática e da digitalização. Enfim, tem-se, mesmo que de maneira ilusória, o acesso a todos os documentos produzidos sobre o objeto que estamos investigando, representados por bits, códigos e sinais eletrônicos, ou seja, "as novas modalidades de produção, de conservação e de conservação do escrito” (GONDRA, 2000, p. 11). Para Chartier (1994), isso exige uma compreensão das formas escritas, desde o códex até as telas dos computadores, e das estratégias de apropriação das materialidades documentais, dando ao leitor a felicidade extravagante prometida pela biblioteca sem paredes.

Essas transformações têm ressignificado o papel das instituições de memória, levando-as a mudar suas estratégias de catalogação e classificação, como forma de agilizar o acesso a fontes documentais (VIDAL, 2000, p. 33). Essas fontes têm sido silenciadas pela dificuldade dos leitores de retirá-las das profundezas das estantes e dar vida e voz a atores sociais que a história dominante manteve esquecidos: vadios, mulheres, crianças pobres e

(C) Revista Digital de Biblioteconomia e Ciência da Informação, Campinas, v. 4, n. esp., p. 01-20, 2006 - ISSN: 1678-765X. 


\section{ARTIGO}

enjeitadas, negros, homossexuais, loucos, operários e outros considerados de pouca relevância e significado para a história oficial (PERROT, 2001).

Os recursos da informática podem contribuir para o resgate do passado, minimizando as dificuldades do pesquisador em localizar e obter as fontes de que necessita para tecer a história ou aclarar alguns de seus pontos. Exemplo disso é o projeto Latin American Microform Project (LAMP) do Center for Research Libraries (CRL), patrocinado pela Fundação Andrew W. Mellon, no qual imagens digitais de séries de publicações emitidas pelo Poder Executivo do Governo do Brasil, bem como pelos governos das províncias, entre 1821 e 1993, podem ser recuperadas e impressas.

Desse modo, as bibliotecas cambiam as suas funções e características, mas, sem dúvida, ainda exercem o seu mais antigo papel de guardiãs do conhecimento. Com isso, trazem como nunca a felicidade extravagante a que nos referimos anteriormente e reacendendo a idéia da biblioteca sem paredes, como almejava o bibliotecário francês Gabriel Naudé, na introdução de sua Bibliografia Política de 1633 e em Advis Pour Dresser Une Bibliothèque de 1627, considerado o primeiro tratado de Biblioteconomia.

Entretanto, como afirma Báez (2006), as bibliotecas foram e sempre serão espaços de disputas pelo poder e fonte de inspiração para a tessituras de outros textos que a tenham como seu objeto de reflexão ou de ficção, como O Nome da Rosa ${ }^{4}$. E certamente os bibliotecários, como seus integrantes, podem aparecer como figuras lendárias, capazes de cercear as práticas leitoras ou como profissionais aptos a operar mudanças sociais. É evidente que isso depende do tempo a ser tratado, dos significados da biblioteca para o escrevente e, principalmente, da forma como a sociedade a concebe, assim como do seu compromisso consigo, com o outro e com o mundo.

4 O cinema tem freqüentemente utilizado bibliotecas como cenários, a exemplo dos filmes e/ou documentários : O preço da liberdade; Todos os homens do presidente; Uma cidade sem passado; O óleo de Lorenzo, Toute la mémorie du monde, Biblioteca Mindlin, Uma Cidade sem Passado, dentre outros. Na literatura, também são muitas as obras com cenas que se passam em bibliotecas: Aqueles cães malditos de Arquelau; A biblioteca mágica de Bibbi Bokkerr; The Memory Mankind: the story of Libraries Since the Dawn of History e muitas outras. 


\section{CONCLUSÃO}

O texto, O Nome da Rosa, evidencia como as bibliotecas se sedimentam na bifurcação estabelecida entre as relações de poder daqueles que governam e controlam o saber e a correlação de forças estabelecida pelos elementos contra-hegemônicos, que burlam as fronteiras demarcadas pelos mais favorecidos economicamente, no intuito de se apropriarem do conhecimento, num contexto dado (HALL, 2001). Desde a mais remota antiguidade até os dias atuais, controle, poder e saber têm caminhado juntos, refletindo-se em cada sociedade a partir das diferentes configurações e diversas roupagens, sem perder em nenhuma delas a sua essência (CORCUFF, 2001). O saber, o conhecimento tem adquirido em todas as sociedades e civilizações valor de mercadoria, podendo ser vendido, transacionado e cerceado. Este aspecto explicita e caracteriza qualquer sociedade, da mais antiga à mais atual, como sociedade da informação, que responde e corresponde a um contexto delimitado e determinado na categoria espaço-tempo. Para Gertz (1989) "todos os estados foram sociedades da informação, pois a geração do poder de Estado pressupõe a reprodução reflexivamente monitorada do sistema, envolvendo a coleta, o armazenamento e o controle regulares da informação aplicada a fins administrativos”.

Não há duvida de que as bibliotecas existem, subsistem e coexistem num mundo cada vez mais mediatizado. Todavia, essa “nova biblioteca” não se alcança pela simples incorporação das tecnologias da informação. A biblioteca se rejuvenesce, se reedifica, ao assumir o papel emancipátorio que se lhe destina.

Mas esse papel depende dos posicionamentos adotados pelos profissionais da informação e por aqueles que, direta ou indiretamente, estão implicados no processo de construção, transmissão e produção do conhecimento - os intelectuais transformadores de Bernstein (1975). Analisando-se as estratégias dos bibliotecários para salvaguardar as memórias societais como patrimônio da humanidade e suas táticas educativas progressistas, conclui-se que, mais do que se inserir num processo tecnológico, as bibliotecas têm que se debruçar num processo de reedificação do ser humano. 


\section{ARTIGO}

Nessa perspectiva, o bibliotecário deve assumir o papel de um ativista do bemestar social, com profunda vocação e convicção sociopolítica. Deve tornar-se um defensor da preservação e da conservação do patrimônio histórico da humanidade. Tem o dever de considerar livros, manuscritos, imagens e sons produzidos no passado como instrumentos para a construção de uma compreensão ampla do tempo presente, garantindo a cada povo e nação uma identidade cultural integrada e legítima, diversa e unitária.

\section{REFERÊNCIAS}

ALEXANDRE-BIDON, D; LORCIN, M.T. Système éducatif et cultures dans l'Occident medieval ( XIIE-XVE Siècle). Paris: Ophrys, 1998.

BÁEZ, F. História universal da destruição dos livros. Rio de Janeiro: Ediouro, 2006.

BARATIN, M.; Christian J. O poder das bibliotecas: a memória dos livros no Ocidente. Rio de Janeiro: Editora UFRJ, 2000.

BATTLES, M. A conturbada história das bibliotecas. São Paulo: Planeta do Brasil, 2003.

BELO, A. História \& história do livro. Belo Horizonte: Autêntica, 2002.

BERLIOZ, J. Monges e religiosos na Idade Média. Lisboa: Terramar, 1996.

BERNESTEIN, B. Class, codes and control. Londres: Routleedge and Kegan Paul, 1975.

BURKE, P. Uma história social do conhecimento: de Gutenberg a Diderot. Rio de Janeiro: Jorge Zahar, 2003.

(C) Revista Digital de Biblioteconomia e Ciência da Informação, Campinas, v. 4, n. esp., p. 01-20, 2006 - ISSN: 1678-765X. 
CALVINO, Í. Um general na biblioteca. São Paulo: Companhia das Letras, 2001.

CANFORA, L. A biblioteca desaparecida: história da biblioteca de Alexandria. São Paulo: Companhia das Letras, 1989.

CASTRO, C. A. Produção e circulação de livros no Brasil: dos Jesuítas (1550) aos militares (1970). Enc. Bibli: R. Eletrônica de Bibl. Ci. Inform. Florianópolis, n.20, 2. semestre, 2005.

CHARTIER, R. A ordem dos livros. Brasília: Editora da UnB, 1994.

Do códige ao monitor: a trajetória do escrito. Estudos Avançados, São Paulo, v.8, n.21, p. 185-199, maio/ago. 1994.

. História cultural entre práticas e representações. Lisboa: DIFEL, 1982.

CERTEUA, M. A invenção do cotidiano: artes de fazer. Petrópolis: Vozes, 1994.

A escrita da história. Rio de Janeiro: Florense, 1982.

CORCUFF, P. As novas sociologias: construções da realidade social. Bauru, SP: Edusc, 2001.

DELEUZE, G. Conversações. São Paulo: Editora 34, 1992.

DUBY, G. A história continua. Rio de Janeiro: Jorge Zahar,1993

ECO, U. O Nome da Rosa . Rio de Janeiro: Record, 1986.

FOUCAULT, M. Arqueologia do saber. 7.ed. Rio de Janeiro: Forense, 2004. 
FOUCAULT, M. Microfísica do poder. Rio de Janeiro: Forense,2004.

FOUCAULT, M. Des espaces autres (1967), Hétérotopies. Architecture, Mouvement, Continuité. Paris, n.5, p.46-49. oct. 1984. acesso em: 13.08.2006. Disponível em: $<$ http:// Foucault, Michel.info/documents/Foucault.hereroTopia.en.html> Acesso: 13.08.2006.

GRANT, E. God and reason in the Middle Ages. Cambridge: Cambridge University Press,2001.

GEERTZ, C. A interpretação das culturas, Rio de Janeiro: koogan, 1989

GINZBURG, C. O queijo e os vermes. São Paulo: Companhia das Letras, 1987.

GONDRA, J. G. A leveza dos bis: história da educação e as novas tecnologias. In: MENDES FILHO, L. F. Arquivos, fontes e novas tecnologias: questões para a história da educação. São Paulo: Autores Associados,2000.

HALBWACHS, M. A memória coletiva. São Paulo: Vértice, 1990.

HALL, S. A identidade cultural na pós-modernidade. Rio de Janeiro: DP\&A, 2001

HUNT, L.. A nova história da escrita. São Paulo: Martins Fontes, 1992.

LE GOLF, J. Os intelectuais na Idade Média. 4.ed. São Paulo: Brasiliense, 1995. O nascimento do purgatório. Lisboa: estampa, 1993.

MATTOSO, J. Poderes invisíveis: o imaginário medieval. Lisboa: Circulo de Leitores, 2001. 
McMURTRIE, D. O livro. $3^{\circ}$ ed. Lisboa: Fundação Calouste Gulbenkian, 1997.

MICHELET, J. A agonia da Idade Média. São Paulo: EDUC, 1992.

MOULIN, L. A vida cotidiana dos estudantes na Idade Média. Lisboa: Livros do Brasil, 1994.

NORA, P. Entre memória e história: a problemática dos lugares. Projeto histórico. São Paulo: n.10, p.7-28, dez. 1993.

NUNES, C.; CARVALHO, M. M. C. Historiografia da educação e fontes. Cadernos ANPED. Porto Alegre, n.5, p.7-64, 1993.

PERROT, M. Os excluídos da história: operários, mulheres, prisioneiros. 3.ed. São Paulo: Paz e Terra, 1988.

SILVA, T. E. Bibliotecas: metáforas da memória. Enc. Bibli: R. Eletr. Bibliotecon. Ci. Inf., Florianópolis, n.21, 1. sem. 2006

VIDAL, D. G. Fim do mundo do fim: avaliação, preservação e descarte documental. In: MENDES FILHO, L. F. Arquivos, fontes e novas tecnologias: questões para a história da educação. São Paulo: Autores Associados,2000. p. 31-44. 


\section{César Augusto Castro}

Professor do Departamento de Biblioteconomia e do Programa de Pós-graduação em Educação da Universidade Federal do Maranhão. Doutor em Educação pela Universidade de São Paulo. Coordenador do Núcleo de História da Educação e das Práticas Leitoras dessa IES. ccampin@terra.com.br

Recebido em: 03/09/2006

Aceito para publicação em: set. 2006 